\title{
Characterization of post-transcriptional RNA modifications by sheathless capillary electrophoresis - high resolution mass spectrometry
}

\author{
Antony Lechner ${ }^{1 *}$, Philippe Wolff ${ }^{2,3^{*}}$, Emmanuelle Leize-Wagner ${ }^{1}$, Yannis-Nicolas François $^{1}$ \\ ${ }^{1}$ Laboratoire de Spectrométrie de Masse des Interactions et des Systèmes (LSMIS) UMR 7140 (Unistra-CNRS), Université de \\ Strasbourg, France. \\ 2 Université de Strasbourg, CNRS, Architecture et Réactivité de l'ARN, UPR 9002, F-67000 Strasbourg, France. \\ ${ }_{3}^{3}$ Plateforme protéomique Strasbourg Esplanade, CNRS, FRC 1589, F-67000 Strasbourg, France. \\ ${ }^{*}$ These authors contributed equally to this work
}

\section{ABSTRACT:}

Since last decade there is a growing interest of RNA modifications analysis. High performance liquid chromatography-tandem mass spectrometry coupling (HPLC-MS/MS) is classically used to characterize post-transcriptional modifications of ribonucleic acids (RNAs). Here we proposed a novel and simple workflow based on capillary zone electrophoresis-tandem mass spectrometry (CE-MS/MS), in positive mode, to characterize RNA modifications at nucleoside and oligonucleotide levels. A first total digestion of purified RNA, prior CE-MS/MS analysis, enables to identify nucleoside modifications. Then, using a bottom-up approach, sequencing of RNAs and mapping of modifications were performed. Sequence coverages from $68 \%$ to $97 \%$ were obtained for four tRNAs. Furthermore, unambiguous identification and mapping of several modifications were achieved.

\section{Corresponding author:}

Dr. Yannis FRANCOIS

Email: yfrancois@unistra.fr, Phone number: +33368851629 


\section{Introduction}

All the classes of RNAs are post-transcriptionally modified. RNA modifications increase the structural and functional diversity of RNA and as a consequence influence RNA structural stability, RNA base pairing and protein recognition. There is poor information on RNA modifications. To increase the knowledge of the community, it is important to use sensitive approaches. Several analytical methods were developed to study RNA modifications. Among them, RNA-seq techniques are the most common approach to locate RNA modifications. However, this method can be limited for the characterization of certain modifications due to blockage mechanism ${ }^{1,2}$. In parallel, mass spectrometry (MS) has increasingly become a valuable technique to investigate modifications because it provides specificity, sensitivity and may also perform structural elucidations ${ }^{3}$. In the last decades, strategies using enzymatic digestions, prior MS detection, were established to study RNA ${ }^{4}$. However, despite the impressive last improvements of MS in terms of resolution and sensitivity, MS often needs to be hyphenated to separation methods in order to perform deeper characterization of biomolecules. Since the report of electrospray ionization (ESI), HPLC-ESI-MS/MS has become rapidly an important and popular tool for the investigation of nucleic acids modifications. Indeed, this tool can be used not only to characterize modifications but also to quantify them 1,5-8. It permitted the discovery of many unknown RNA modifications which, at this day, represent more than 160 natural chemical modifications reported in the literature ${ }^{9}$. Capillary zone electrophoresis (CZE) is a complementary method to liquid chromatography. In CZE, analytes are separated under an electrical field which offers different selectivity. In addition, CZE has major advantages as low sample consumption, fast and effective separations. CE equipped with optical detection were abundantly reported to study RNA at different levels ${ }^{10-}$ 13. However, no structural information can be extracted from this type of detector and/or standards should be used to identify modifications ${ }^{14-16}$. Hyphenation of CE-MS was a long time challenging due to the necessity to maintain two independent voltages (separation voltage and electrospray voltage). Since its first report in the late $80^{\prime}$ s by Olivares et al. ${ }^{17}, \mathrm{CE}$ coupled with MS became of high interest for the analysis of biologics ${ }^{18}$. Concerning RNA analysis, Feng et al developed, in 2007, the pressure assisted electrokinetic injection technique to measure oligonucleotides and their adducts ${ }^{19}$. In 2016, Khan et al reported the use of CE-MS to directly characterize modifications of microRNAs in cancer serum ${ }^{20}$. CZE 
coupled to MS was also used to estimate rate and equilibrium constant of the conformational dynamics of DNA G-Quadruplex ${ }^{21}$. More recently, Demelenne et al. performed CZE-MS analysis in order to characterize therapeutic olignoculeotides ${ }^{22}$. Different geometries of interface were developed since the first CE-MS hyphenation ${ }^{23}$. In 1997, Moini et al developed a sheathless interface ${ }^{24}$. The design of this interface has the ability to generate a nanoESI and provides an excellent sensitivity ${ }^{25}$. Indeed, several articles reported the use of this sheathless interface in many fields of application as metabolomic ${ }^{26}$, proteomic ${ }^{27}$ or glycomic ${ }^{28,29}$. RNA modifications are chemical changes that generally lead to a mass shift and/or charge shift. Recently, Yu et al reported the first study about the quantification of eight RNA modified nucleotides by multiple reaction monitoring (MRM) using CZE-ESI-MS/MS ${ }^{30}$. In this work, a simple workflow based on CZE-ESI-MS/MS was developed in order to characterize RNA posttranscriptional modifications at two different levels using the same CZE experimental conditions. Although RNA are classically detected in negative ion mode, in the present study, detection of analytes were achieved in positive ion mode. In a first approach, we performed a total hydrolysis of RNA to screen modifications at the nucleoside level, then, a bottom-up approach was developed with the aim of sequencing RNA and mapping the modifications at the oligonucleotide level. The implemented strategy permitted to highlight the modifications present on the RNAs but also to locate them on the primary structure. For this study, four purified and desalted tRNA from $S$. cerevisiae (tRNA ${ }^{A s p G U C ;}$ tRNA ${ }^{A l a A G C}$; tRNA ${ }^{\text {TrpCCA }}$ and tRNA $^{\text {PheGAA) }}$ were selected as model molecules. These tRNAs contain about 75 nucleic acids and their sequences and modifications (type and location) are well-known and already described in the literature ${ }^{9,31}$.

\section{Materials and Methods}

Chemicals and Reagents. Chemicals used were of analytical grade or high purity. Water used to prepare samples solutions or buffers was obtained using a Direct- $Q^{\circledR} 3$ UV-R water purification system (Merck Millipore, Amsterdam, The Netherlands). Bacterial Alkaline Phosphatase (BAP) (150 U/ $\mu \mathrm{L})$, RNase T1 and RNase A were purchased from ThermoFisher Scientific (Marietta, OH, USA). RNase P1 from Penicillum citrinum was purchased from SigmaAldrich (Saint Louis, MO, USA) 
Sample preparation. Purified tRNAs from S. cerevisiae (tRNA ${ }^{A s p G U C}$; tRNA ${ }^{A l a A G C}$, tRNA $^{\text {TrpCCA }}$ and tRNA ${ }^{\text {PheGAA) }}$ are homemade prepared and desalted by three successive precipitations with ammonium acetate. For nucleoside analysis, tRNAs were diluted to a concentration of $2 \mu \mathrm{g} / \mu \mathrm{L}$ in $\mathrm{H}_{2} \mathrm{O}$. Digestion was carried out in this order: $7 \mu \mathrm{L} \mathrm{H} \mathrm{H}_{2} \mathrm{O} ; \mu \mathrm{L}$ buffer $\mathrm{P} 110 \mathrm{X}(2 \mathrm{mM} \mathrm{ZnCl}$, $\left.250 \mathrm{mM} \mathrm{NH}_{4} \mathrm{OAc}, \mathrm{pH} 5.0\right) ; 1 \mu \mathrm{L}$ of tRNA and $1 \mu \mathrm{L}$ of $\mathrm{P} 1(0.5 \mathrm{U} / \mu \mathrm{L})$. Mixture was incubated at $37^{\circ} \mathrm{C}$ for 2 hours. After $\mathrm{P} 1$ digestion, $10 \mu \mathrm{L}$ of BAP (1.5 U/ $\mu \mathrm{L}$ in $\left.100 \mathrm{mM} \mathrm{NH}_{4} \mathrm{OAc}\right)$ was added to the mixture and incubated at $37^{\circ} \mathrm{C}$ for 4 hours. The mixture was diluted 2 times in $\mathrm{NH}_{4} \mathrm{OAc} 200$ $\mathrm{mM} \mathrm{pH} 4$ and analyzed by CE-MS/MS. For oligonucleotides analysis, tRNAs were diluted to a concentration of $0.75 \mu \mathrm{g} / \mu \mathrm{L}$. For RNase T1 digestion, a solution of $100 \mu \mathrm{L}$ of RNase T1 (1/1000 in $\left.\mathrm{NH}_{4} \mathrm{OAc} 100 \mathrm{mM}\right)+0.5 \mu \mathrm{L}$ of BAP $(150 \mathrm{U} / \mu \mathrm{L})$ was made. $10 \mu \mathrm{L}$ of this solution $+1 \mu \mathrm{L}$ of tRNA were mixed and samples were incubated for overnight at $37^{\circ} \mathrm{C}$. Then, the mixture was directly analyzed by CE-MS/MS. For RNase A digestion, a solution of $1000 \mu \mathrm{L}$ of RNase $A(1 / 1000$ in $\left.\mathrm{NH}_{4} \mathrm{OAc} 100 \mathrm{mM}\right)+0.5 \mu \mathrm{L}$ of BAP $(150 \mathrm{U} / \mu \mathrm{L})$ was made. $10 \mu \mathrm{L}$ of this solution $+1 \mu \mathrm{L}$ of tRNA were mixed and samples were incubated for overnight at $37^{\circ} \mathrm{C}$. Then, the mixture was directly analyzed by CE-MS/MS.

Capillary electrophoresis. All of the CE experiments have been done on a CESI8000 capillary electrophoresis system from Sciex Separation (Brea, CA, USA). The 32 Karat $^{T M}$ (Sciex separation) software was used for instrument control and data acquisition. Samples were stored at $7{ }^{\circ} \mathrm{C}$ in sample tray before injection. Bare fused-silica capillary (total length $100 \mathrm{~cm}$; $30 \mu \mathrm{m}$ i.d.) with porous tip on its final end, a second capillary filled during experiments with BGE (10\% acetic acid) allows electrical contact. Conditioning of a new capillaries was performed by applying 10 min 50 psi of $\mathrm{NaOH} 1 \mathrm{M}, \mathrm{NaOH} 0.1 \mathrm{M}$ and $\mathrm{H}_{2} \mathrm{O}$. For CE experiments, hydrodynamic injection (4 psi for $9.1 \mathrm{sec}$ ) corresponding to a total volume of $5 \mathrm{~nL}$ of sample injected was used (for total and partial digestions). Separations were achieved applying +30 kV. After each run, capillary was rinsed by applying 1 min 100 psi of $\mathrm{MeOH}, \mathrm{H}_{2} \mathrm{O}, \mathrm{NaOH} 0.1 \mathrm{M}$, $\mathrm{H}_{2} \mathrm{O}, \mathrm{HCl} 0.1 \mathrm{M}, \mathrm{H}_{2} \mathrm{O}$ and 2 min 100 psi of BGE.

Mass spectrometry. For nucleoside analysis, the CE system was coupled to a maXis $4 \mathrm{G}$ mass spectrometer (Bruker, Bremen, Germany) by the sheathless interface. The maXis MS is equipped with a hybrid analyzer composed of quadrupoles followed by time-of-flight (TOF). The Otof control 3.4 software allowed to pilot the nanoESI source. Source settings were the 
following ones: Ion polarity: positive, nanoESI voltage: $+1500 \mathrm{~V}$, Source heating temperature: $130{ }^{\circ} \mathrm{C}$, Dry gas: $1.2 \mathrm{~L} / \mathrm{min}$, Mass/charge (m/z) range was $80-800$ for MS and MS/MS detection. Gas-phase fragmentations were performed using $\mathrm{N}_{2}$. Collision energies were set at $20 \mathrm{eV}$ for CID experiments. For oligonucleotide analysis, the same source parameters were used except for $\mathrm{m} / \mathrm{z}$ range which was 230-2300 for MS and MS/MS detection. Gas-phase fragmentations were performed using $\mathrm{N}_{2}$. Collision energies for CID experiments were ranged from 6 to $48 \mathrm{eV}$ according to $\mathrm{m} / \mathrm{z}$ ratio of precursors.

Data analysis. Data obtained from CE-MS/MS experiments were analyzed using DataAnalysis software (Bruker, Bremen, Germany). All data were manually interpreted. Sequences of tRNA as well as locations of structures of modified nucleotides were found in Modomics database (http://modomics.genesilico.pl/sequences/list/tRNA/). This database is constantly verified and regularly updated. $\mathrm{m} / \mathrm{z}$ ratios of theoretical digest products were simulated using MongoOligo mass calculator v2.08 (https://mods.rna.albany.edu/masspec/Mongo-Oligo). The $\mathrm{m} / \mathrm{z}$ ratios of fragment ions generated by CID experiments were also calculated by MongoOligo. It is important to note that RNase T1 and RNase A cleave RNA after specific nucleotides, but could also cleave after certain modified nucleotides. For example, RNase T1 cleaves after $\mathrm{m} 2 \mathrm{G}$ and RNase A cleave after D and $\mathrm{m} 5 \mathrm{U}$. MongoOligo simulator ( $\mathrm{v} 2.08$ ) does not cleave modifications and checking of simulated fragments from this calculator should be done.

For the analysis of total hydrolysis, theoretical $\mathrm{m} / \mathrm{z}$ of unmodified and modified compound were extracted with a tolerance of $\pm 0.02 \mathrm{~m} / \mathrm{z}$. Identification of compounds were done using migration times, precursor ions and product ions.

For the analysis of oligonucleotides, theoretical $\mathrm{m} / \mathrm{z}$ of compounds were extracted with a tolerance of $\pm 0.02 \mathrm{~m} / \mathrm{z}$. Identifications of digested RNA fragments were done from CID spectra by reconstructing the sequence following $y$ and/or c series. If not possible, other series can be used. Modifications are localized with the same procedure. Then experimental results were confronted with theoretical. 


\section{Results and discussion}

\section{Characterization at the nucleoside level}

To study RNAs modifications, classical strategies based on different ribonucleases (RNases) were assessed ${ }^{5,7}$. The first level of characterization consisted to perform the total hydrolyses of the sample with the aim of identifying modified nucleotides present in the RNAs. This step was performed using ribonuclease P1 (RNase P1) which cleaves 3' phosphate of any nucleotide. Remaining 5' phosphates were removed using bacterial alkaline phosphatase (BAP) to obtain a mixture of nucleosides. A 30 minutes separation of ribonucleosides were achieved by applying $+30 \mathrm{kV}$ with a background electrolyte constituted of $10 \%$ acetic acid $(\mathrm{pH}$ 2.2) and a sample volume of $5 \mathrm{~nL}$ (corresponding to $10 \mathrm{fmol}$ injected) ${ }^{30}$. While RNA are classically detected in negative ion mode due to their acidic property, exploring the positive mode can provide another facet of RNA analysis and thus could show complementarity. To screen modified nucleosides, the analytes were then on-line detected by CZE-ESI-MS/MS in positive ion mode. Extracted lon Electropherograms of nucleosides from $\mathrm{TRNA}^{\text {PheGAA }}$ are shown in Figure 1 (for other tRNA, see Supporting Information Figure S1 to S3). As expected, the four canonical nucleosides and modified nucleosides were separated and characterized with \pm 0.02 $\mathrm{m} / \mathrm{z}$. To increase identification confidence, MS/MS of nucleosides was performed. For peaks assignments, identifications were confirmed when specific transition were detected ${ }^{32}$. For example, in the case of uridine and pseudouridine, these species were identified using MS/MS spectra because these isomers have different fragmentation patterns. However, these methods cannot distinguish nucleosides having the same fragmentation pattern. In that case, standards need to be used to characterize modification based on their migration times. For

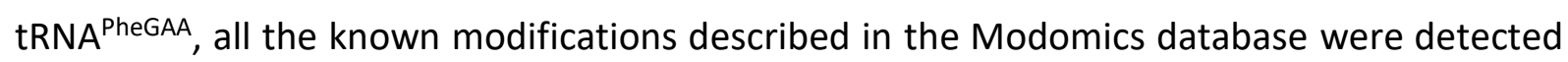
and compiled in Table 1 (for other tRNA, see Supporting Information Table S1 to S3). The most important and common modified nucleosides were identified as dihydrouridine (D) and methylated nucleosides, however, in the same set of data, other more complex modifications as wybutosine $(\mathrm{yW})$ were also characterized. Interestingly, in the case of tRNA ${ }^{\text {TrpCCA }}$ which contains four methylated guanosines (1-methylguanosine $\mathrm{m}^{1} \mathrm{G}$; N2-methylguanosine $\mathrm{m}^{2} \mathrm{G} ; 2^{\prime}$ O-methylguanosine $\mathrm{Gm}$ and 7-methylguanosine $\mathrm{m}^{7} \mathrm{G}$ ), separation of these isomers were achieved using CZE-ESI-MS/MS as shown in Figure 2. The excellent separation provided by CZE enables the best selectivity for these isomers. While $\mathrm{Gm}$ was characterized with its different 
fragmentation pattern and $\mathrm{m}^{7} \mathrm{G}$ with the analysis of P1 digested tRNA Val from S. cerevisiae standard (data not shown), $\mathrm{m}^{1} \mathrm{G}$ and $\mathrm{m}^{2} \mathrm{G}$ were not assigned because the standards were not available. Thus, we demonstrated the ability of CZE-ESI-MS/MS to easily screen and identify all modifications contained in the four tRNA. However, this level of characterization does not allow to locate modifications on RNA sequences.

\section{Characterization at the oligonucleotide level}

Hence, a strategy was implemented to map modified nucleotides on the RNA sequence. In addition to the location of previously identified modifications, primary structure characterization was simultaneously assessed using the same set of data. For this purpose, a bottom-up approach was developed using exactly the same CZE-ESI-MS/MS conditions used for ribonucleosides characterization. Based on a proteomic-like strategy, RNase digestions have been performed to obtain a pool of short oligonucleotides. To increase sequence coverages, a workflow based on two specific digestions was realized. Prior CZE-ESI-MS/MS analysis, samples were individually digested by RNase T1 and RNase A ${ }^{33,34}$. RNase T1 cleaves specifically at 3' end of guanosine while RNase A cleaves specifically at 3' end of pyrimidines. Major advantages of these RNases are their strong specificity and their excellent reactivity involving the production of no miscleavages. In addition, dephosphorylation of terminal phosphates using BAP was also performed simultaneously to each digestion to improve separation (data not shown) and facilitate MS/MS spectra interpretation ${ }^{35}$. Following digestion step, oligonucleotides were analyzed in 60 to 80 minutes by CZE-ESI-MS/MS in positive polarity using the same experimental conditions described for the ribonucleosides study. The similarity of experimental conditions is a very important advantage in terms of analysis time because it allows to perform the two levels of characterization without any instrumental and experimental modification. In comparison with LC-MS workflows, analysis of nucleosides and oligonucleotides have different experimental conditions (column, nature of mobile phase, etc.), which considerably complicates the implementation of RNA characterization at different levels and consequently increases the analysis time. Following the CZE-ESI-MS detection, fragmentation of oligonucleotides by MS/MS experiments were achieved using collision-induced dissociation (CID). Nowadays, softwares for data treatment of MS and MS/MS spectra of RNA were developed (RNAModMapper ${ }^{36}$, RoboOligo ${ }^{37}$ or Ariadne ${ }^{38}$ ), however, they are not yet available in positive mode. Then, we carried out the 
manual interpretation of MS/MS raw data in order to avoid errors for unambiguous mapping of modifications. Excellent separations of RNase T1 and RNase A oligonucleotides were achieved by CZE-ESI-MS/MS for each tRNA, facilitating significantly MS spectra interpretation. As an example, extracted ion electropherogram of oligonucleotides are shown in Figure 3 for tRNA ${ }^{\text {PheGAA }}$ (For other tRNA, see Supporting Information Figure S4 to S9). MS/MS spectra were also manually interpreted. Primary structures were reconstructed following the $y$ and/or c series ${ }^{39}$. a-B and $w$ ions can also be useful if the sequencing is difficult or to confirm the sequence. To validate oligonucleotides, we have considered only the ones whose were detected in MS and fully sequenced by MS/MS. For the larger ones, we often get MS spectra but sometimes they were not abundant enough to be fragmented. Therefore it drops the sequence coverage. It is also important to note that specific RNases produce mononucleotides or dinucleotides that are generally not sequence specific, hence diminishing the sequence recoveries. In our study, only unique mono- and dinucleotides were considered for sequence recoveries. Isobaric species also represent a common issue for RNA sequencing. For example, in the case of RNase T1 hydrolysis of tRNA ${ }^{A s p G U C}$, fragments AUAG and AAUG were product. The performances of CE separation combined with the MS/MS spectral quality allow to characterize without any ambiguity both isobaric species (Figure 4). Finally, compiling the two digestions, sufficient number of sequence specific oligonucleotides were detected by MS and MS/MS to obtain the sequence recoveries from $68 \%$ to $97 \%$ for studied tRNAs. Concerning RNA modifications, same manual data treatment has been realized to locate modifications on RNA sequence. Calculated $\mathrm{m} / \mathrm{z}$ ratio corresponding to modified oligonucleotides have been extracted using MS spectra and sequenced using MS/MS spectra. The Figure 5 shows an example of $M S / M S$ sequencing for ${ }^{13} \mathrm{AA}[\mathrm{yW}] \mathrm{A}[\psi]$ oligonucleotide. Here, the fragment of $377.15 \mathrm{~m} / \mathrm{z}(\mathrm{z}=1)$ correspond to the fragmentation of this modified nucleoside [yW]. Thus, loss of the modified base must be considered to sequence this oligonucleotide. Deduction of 376.15 Da was done for the fragments ions whose contains the modified base and permitted the successful sequencing of this modified oligonucleotide. MS/MS spectral quality allowed precise location of the modified nucleotides on sequences. However, if CZE-ESI-MS/MS analysis of RNA digests enables to determine the precise position onto RNA sequence, in the case of methylation it does not allow to locate the modification on the ribose and/or base. Furthermore, the list of identified fragments by the CZE-ESI-MS/MS analysis were summarized

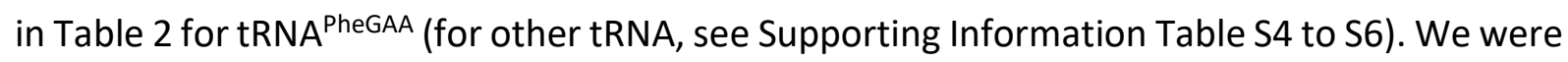


able to locate a large number of modifications previously characterized at the nucleoside level, including the wybutosine modification on RRNA $^{\text {PheGAA }}$.

\section{Conclusion}

To summarize, we developed a simple CZE-ESI-MS/MS workflow for the successful characterization of post-transcriptional RNA modifications. Based on strategies using three different ribonucleases, RNA sequencing and modification characterization have been performed at nucleoside and oligonucleotide levels. Using the same platform with the same experimental conditions, we managed to obtain excellent sequence recoveries and were able to identify and map modifications onto primary sequences of tRNAs. CE-MS/MS could become a powerful tool for unambiguous chemical characterization and sequence placement of modifications onto tRNAs sequences (including mitochondrial tRNAs) with software support. Moreover, CE-MS/MS could be applied to other modified non-coding RNA, especially ribosomal RNAs.

\section{Acknowledgements}

Authors would like to thank Sciex and Bruker Daltonics for the fruitful collaboration and their support. This work was supported by the CNRS (UMR 7140), the University of Strasbourg. Authors would also like to thank Gérard Keith, old member of the IBMC (institut de biologie moléculaire et cellulaire, Strasbourg, France) for the tRNA preparations. 


\section{References}

(1) Carell, T.; Brandmayr, C.; Hienzsch, A.; Müller, M.; Pearson, D.; Reiter, V.; Thoma, I.; Thumbs, P.; Wagner, M. Angew. Chem. Int. Ed. 2012, 51, 7110-7131.

(2) Motorin, Y.; Helm, M. Genes 2019, 10, 35.

(3) Hunt, D. F.; Hignite, C. E.; Biemann, K. Biochem. Biophys. Res. Commun. 1968, 33, 378-383.

(4) Crain, P. F. Method Enzymol. 1990, 193, 782-790.

(5) Kowalak, J. A.; Pomerantz, S. C.; Crain, P. F.; Mccloskey, J. A. Nucleic Acids Res. 1993, 21, 4577-4585.

(6) Cai, W. M.; Chionh, Y. H.; Hia, F.; Gu, C.; Kellner, S.; McBee, M. E.; Ng, C. S.; Pang, Y. L. J.; Prestwich,

E. G.; Lim, K. S.; Babu, I. R.; Begley, T. J.; Dedon, P. C. Rna Modification 2015, 560, 29-71.

(7) Ross, R. L.; Cao, X. Y.; Limbach, P. A. Biomolecules 2017, 7.

(8) Thomas, B.; Akoulitchev, A. V. Trends Biochem. Sci. 2006, 31, 173-181.

(9) Boccaletto, P.; Machnicka, M. A.; Purta, E.; Piatkowski, P.; Baginski, B.; Wirecki, T. K.; de CrecyLagard, V.; Ross, R.; Limbach, P. A.; Kotter, A.; Helm, M.; Bujnicki, J. M. Nucleic Acids Res. 2018, 46, D303-D307.

(10) Jiang, X. M.; Xia, Z. N.; Wei, W. L.; Gou, Q. J. Sep. Sci. 2009, 32, 1927-1933.

(11) Li, N.; Nguyen, A.; Diedrich, J.; Zhong, W. W. J. Chromatogr. A 2008, 1202, 220-223.

(12) Zabzdyr, J. L.; Lillard, S. J. J. Chromatogr. A 2001, 911, 269-276.

(13) Saevels, J.; Van Schepdael, A.; Hoogmartens, J. Anal. Biochem. 1999, 266, 93-101.

(14) Skeidsvoll, J.; Ueland, P. M. Electrophoresis 1996, 17, 1512-1517.

(15) Liebich, H. M.; Xu, G.; Di Stefano, C.; Lehmann, R. J. Chromatogr. A 1998, 793, 341-347.

(16) Cornelius, M. G.; Schmeiser, H. H. Electrophoresis 2007, 28, 3901-3907.

(17) Olivares, J. A.; Nguyen, N. T.; Yonker, C. R.; Smith, R. D. Anal. Chem. 1987, 59, 1230-1232.

(18) Kleparnik, K. Electrophoresis 2015, 36, 159-178.

(19) Feng, Y.-L.; Lian, H.; Zhu, J. J. Chromatogr. A 2007, 1148, 244-249.

(20) Khan, N.; Mironov, G.; Berezovski, M. V. Anal. Bioanal. Chem. 2016, 408, 2891-2899.

(21) Mironov, G. G.; Okhonin, V.; Khan, N.; Clouthier, C. M.; Berezovski, M. V. ChemistryOpen 2014, 3, 58-64.

(22) Demelenne, A.; Gou, M.-J.; Nys, G.; Parulski, C.; Crommen, J.; Servais, A.-C.; Fillet, M. J. Chromatogr. A 2020, 1614, 460716.

(23) Neusüss, C.; Römer, J.; Höcker, O.; Jooß, K., In Capillary electrophoresis Separation Methods, Poole, C., Eds.; Elsevier, 2018, pp 293-311.

(24) Cao, P.; Moini, M. J. Am. Soc. Mass Spectr. 1997, 8, 561-564.

(25) Gahoual, R.; Busnel, J. M.; Wolff, P.; Francois, Y. N.; Leize-Wagner, E. Anal. Bioanal. Chem. 2014, 406, 1029-1038.

(26) Sánchez-López, E.; Kammeijer, G. S. M.; Crego, A. L.; Marina, M. L.; Ramautar, R.; Peters, D. J. M.; Mayboroda, O. A. Sci. Rep. 2019, 9, 806.

(27) Han, X.; Wang, Y.; Aslanian, A.; Bern, M.; Lavallee-Adam, M.; Yates, J. R. Anal. Chem. 2014, 86, 11006-11012.

(28) Kammeijer, G. S. M.; Jansen, B. C.; Kohler, I.; Heemskerk, A. A. M.; Mayboroda, O. A.; Hensbergen, P. J.; Schappler, J.; Wuhrer, M. Sci. Rep. 2017, 7, 3733.

(29) Giorgetti, J.; D'Atri, V.; Canonge, J.; Lechner, A.; Guillarme, D.; Colas, O.; Wagner-Rousset, E.; Beck, A.; Leize-Wagner, E.; Francois, Y. N. Talanta 2018, 178, 530-537.

(30) Yu, Y.; Zhu, S. H.; Yuan, F.; Zhang, X. H.; Lu, Y. Y.; Zhou, Y. L.; Zhang, X. X. Chem. Commun. 2019, 55, 7595-7598.

(31) Kellner, S.; Neumann, J.; Rosenkranz, D.; Lebedeva, S.; Ketting, R. F.; Zischler, H.; Schneider, D.; Helm, M. Chem. Commun. 2014, 50, 3516-3518.

(32) Su, D.; Chan, C. T. Y.; Gu, C.; Lim, K. S.; Chionh, Y. H.; McBee, M. E.; Russell, B. S.; Babu, I. R.; Begley, T. J.; Dedon, P. C. Nat. Protoc. 2014, 9, 828-841.

(33) Antoine, L.; Wolff, P.; Westhof, E.; Romby, P.; Marzi, S. Biochimie 2019, 164, 60-69. 
(34) Antoine, L.; Wolff, P. In RNA Spectroscopy: Methods and Protocols, Arluison, V.; Wien, F., Eds.; Springer US: New York, NY, 2020, pp 101-110.

(35) Krivos, K. L.; Addepalli, B.; Limbach, P. A. Rapid Commun. Mass Spectrom. 2011, 25, 3609-3616.

(36) Lobue, P. A.; Yu, N. X.; Jora, M.; Abernathy, S.; Limbach, P. A. Methods 2019, 156, 128-138.

(37) Sample, P. J.; Gaston, K. W.; Alfonzo, J. D.; Limbach, P. A. Nucleic Acids Res. 2015, 43.

(38) Nakayama, H.; Akiyama, M.; Taoka, M.; Yamauchi, Y.; Nobe, Y.; Ishikawa, H.; Takahashi, N.; Isobe, T. Nucleic Acids Res. 2009, 37.

(39) Mcluckey, S. A.; Habibigoudarzi, S. J. Am. Soc. Mass Spectr. 1994, 5, 740-747. 


\section{Caption:}

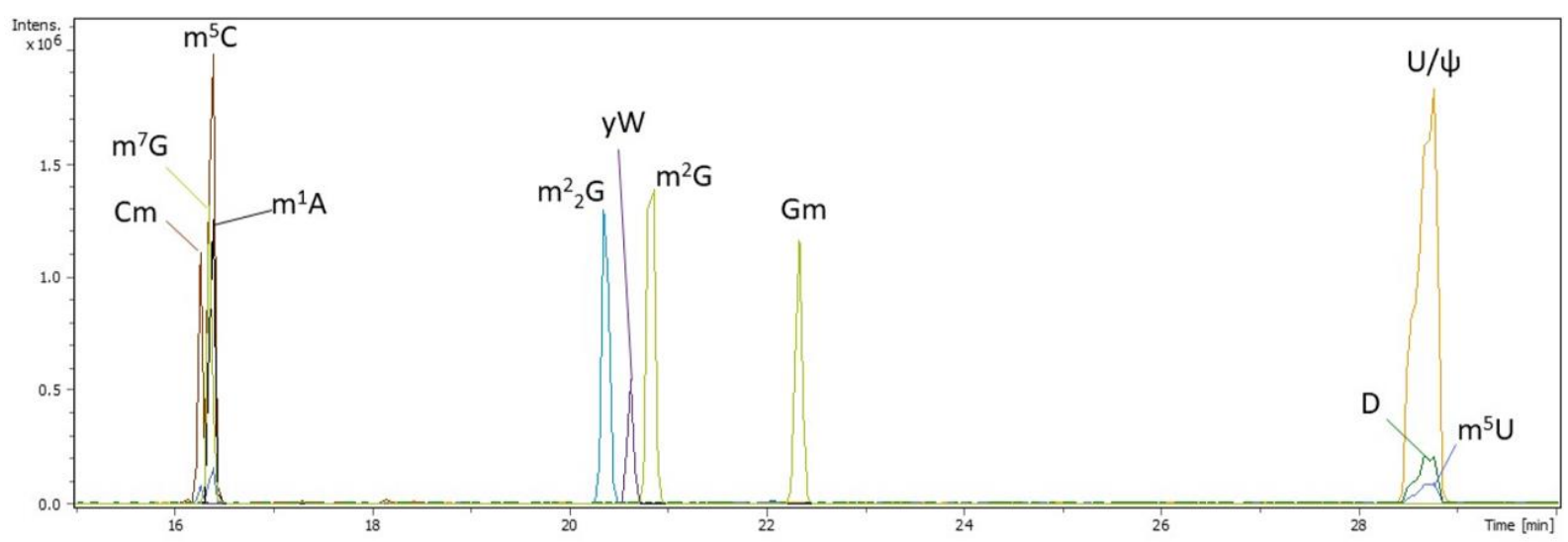

Figure 1 Multiple extracted ion electropherograms for the analysis of RNase P1 BAP digested tRNA ${ }^{\text {PheGAA }}$ from $S$. cerevisiae by CE-MS in positive ion mode, only modified bases are extracted. Injected volume $5 \mathrm{~nL}$ (10 fmol)

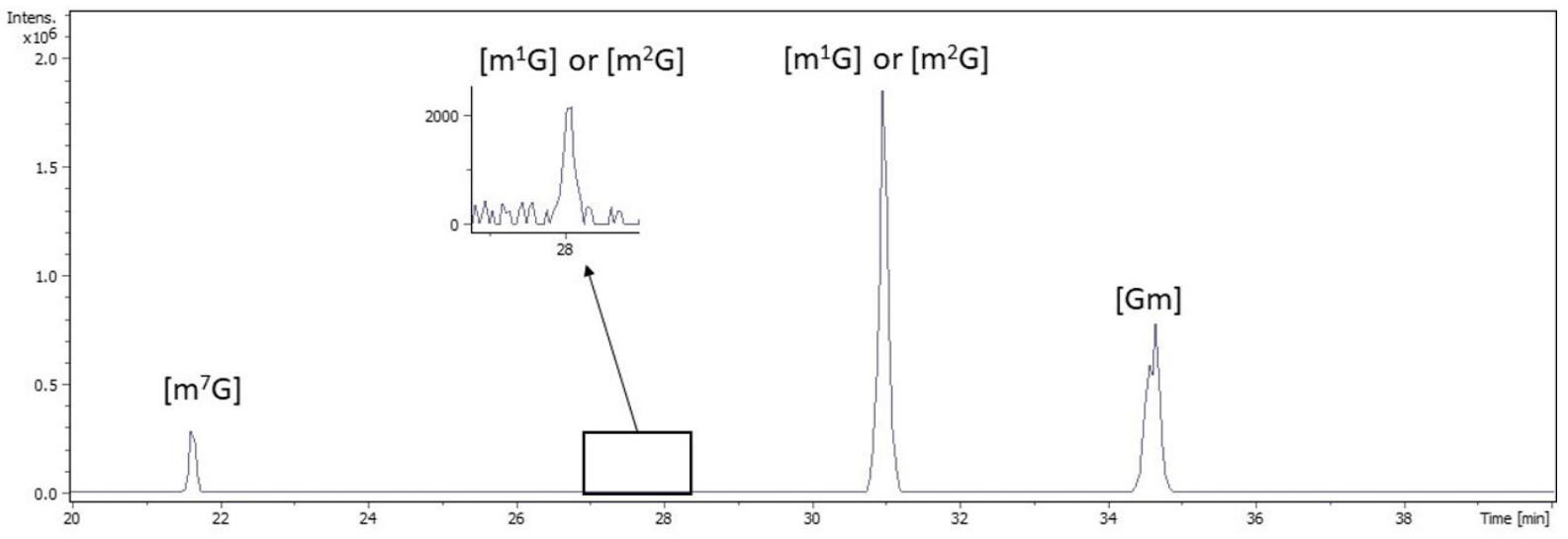

Figure 2 Extracted ion electropherograms of $298.12 \mathrm{~m} / \mathrm{z}$ for the analysis of RNase P1 BAP digested tRNA $^{\text {TrpCCA }}$ by CE-MS/MS in positive ion mode. Injected volume $5 \mathrm{~nL}$ (10 fmol) 

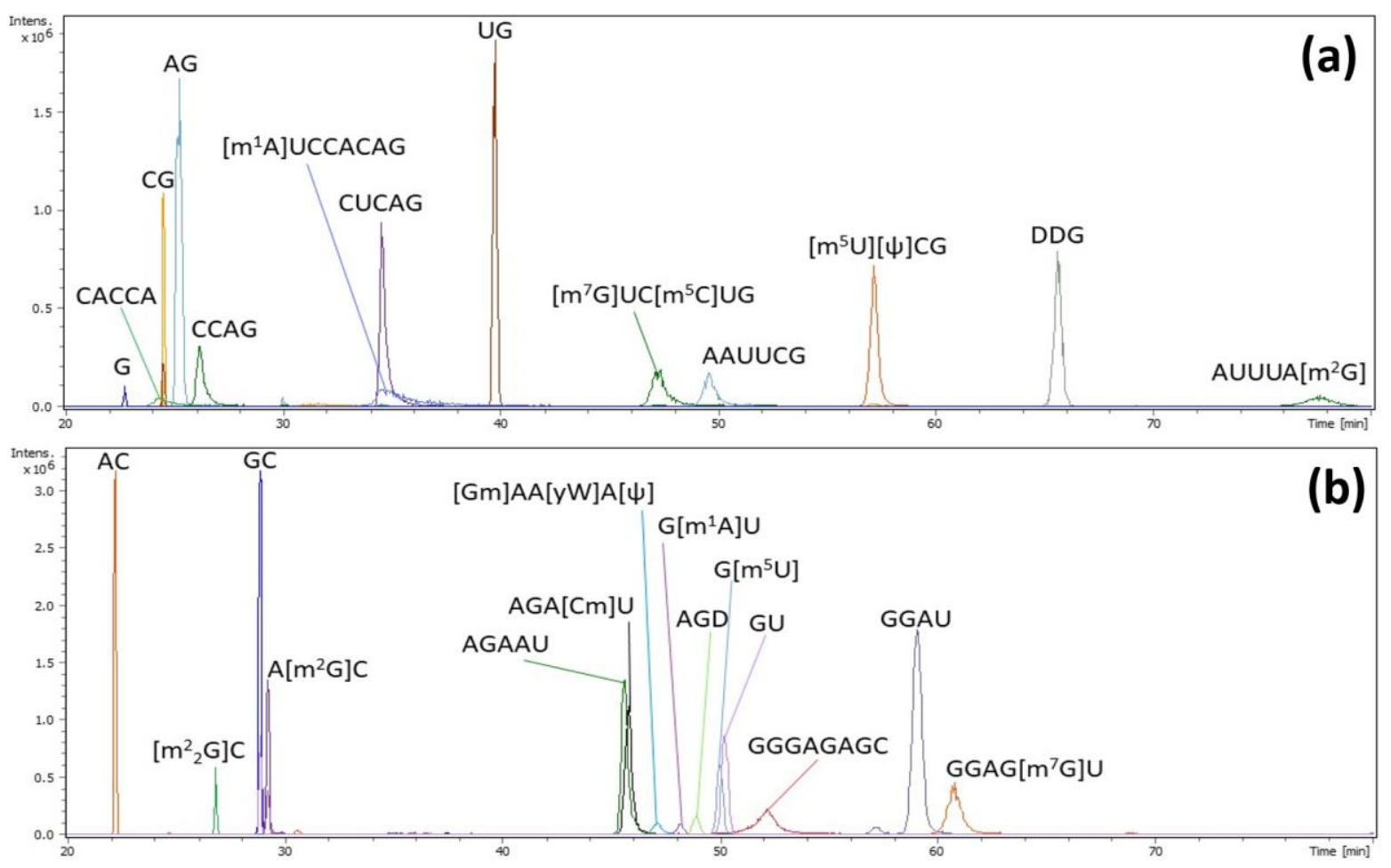

Figure 3 Multiple extracted ion electropherograms for the analysis of (a) RNase T1 BAP and (b) RNase A BAP digested tRNA ${ }^{\text {PheGAA }}$ by CE-MS in positive ion mode. Injected volume $5 \mathrm{~nL}$ (10 fmol)
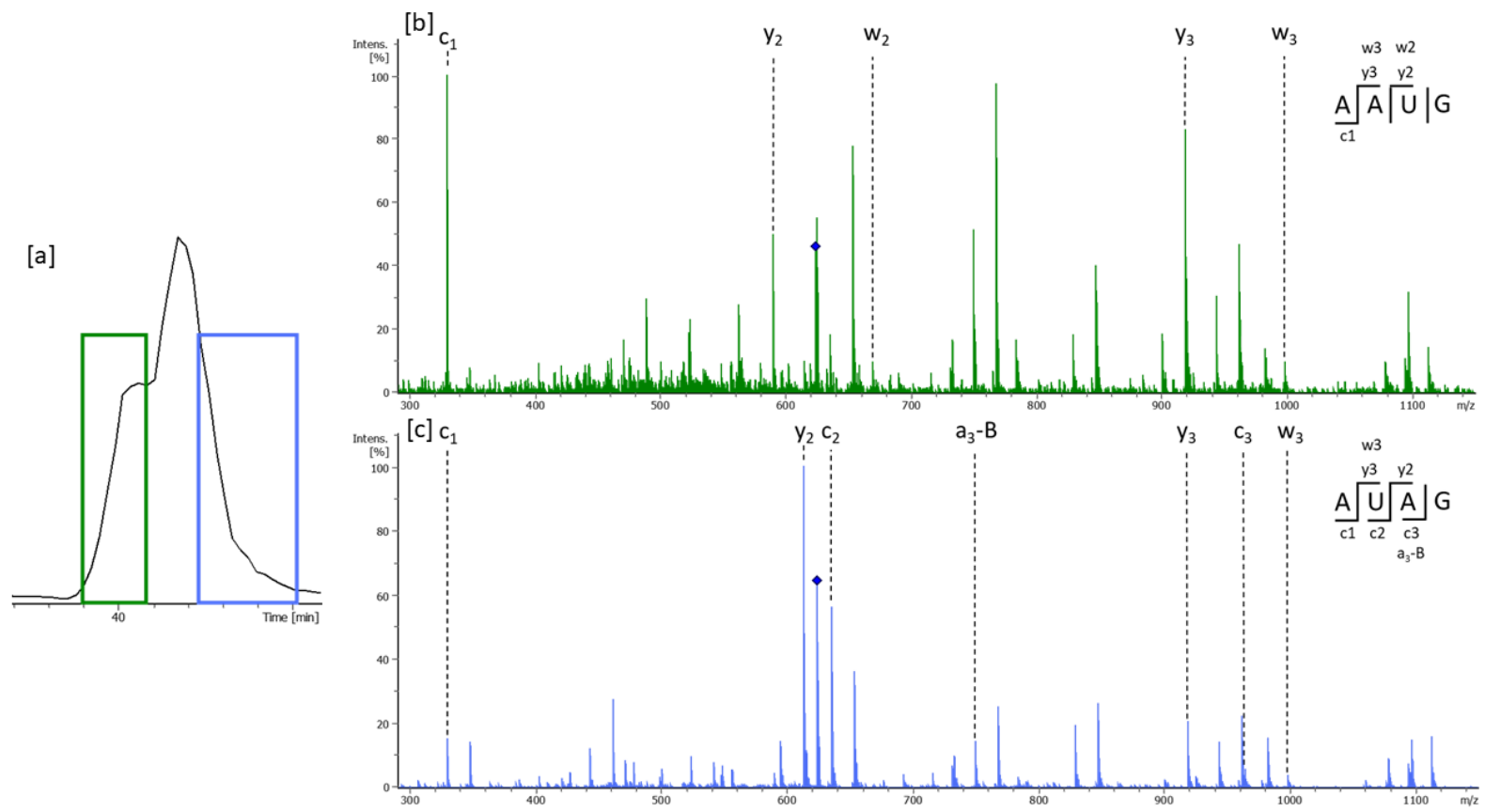

Figure 4 [a] Extracted ion electropherograms of $\mathrm{m} / \mathrm{z} 624.2$ corresponding to the tRNA ${ }^{\text {AspGUC }}$ RNase T1 digestion products AAUG and AUAG [b] CID mass spectrum of $\mathrm{m} / \mathrm{z} 624.21 @ 39.9 \mathrm{~min}$ and [c] CID mass spectrum of m/z $624.21 @ 40.4$ min 


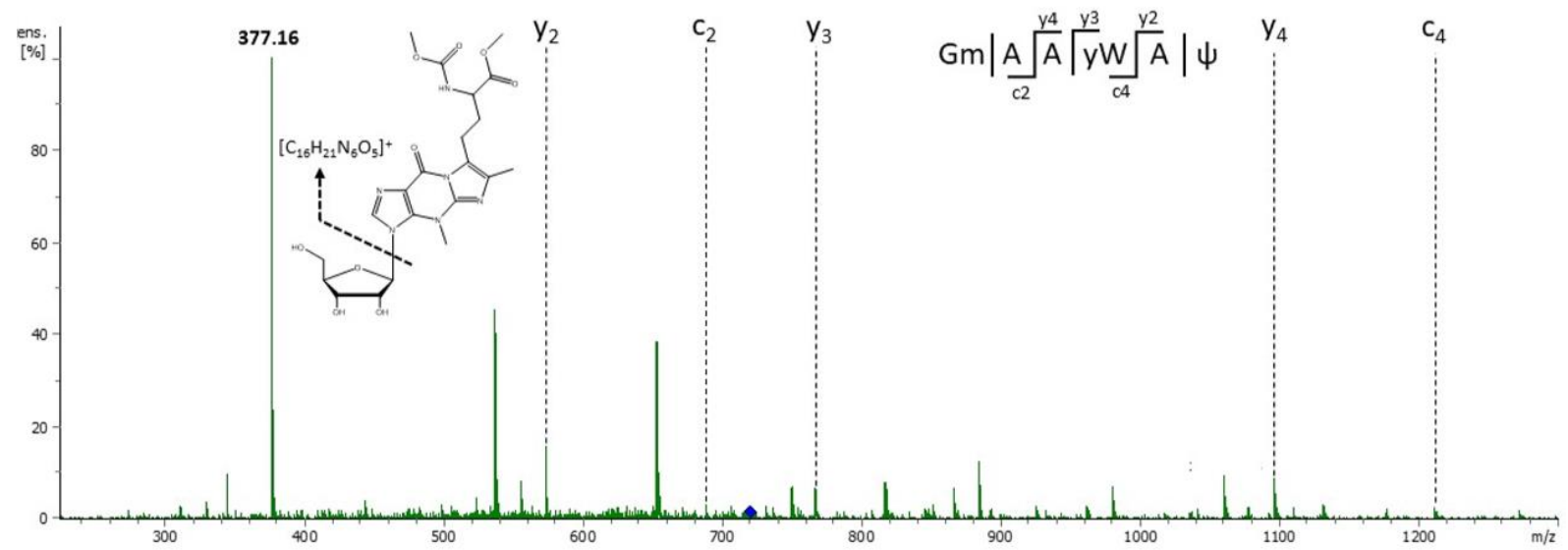

Figure $5 \mathrm{CID}$ mass spectrum of RNase A product ${ }^{13} \mathrm{AA}[\mathrm{yW}] \mathrm{A}[\psi](\mathrm{m} / \mathrm{z} 721.15)$ from $S$. cerevisiae tRNA ${ }^{\text {PheGAA }}$ with fragmentation assignments. Peak of $\mathrm{m} / \mathrm{z} 377.16$ correspond to the loss of the modified base $y W$. 
Table 1. List of all digested products experimentally observed for tRNA ${ }^{\text {PheGAA }}$, after digestion with RNase P1 BAP and CE-MS/MS analysis.

\begin{tabular}{ccccc}
\hline $\begin{array}{c}\text { Precursor ion } \\
(\mathrm{m} / \mathrm{z})\end{array}$ & $\begin{array}{c}\text { Product ion } \\
(\mathrm{m} / \mathrm{z})\end{array}$ & Molecular mass (Da) & Migration time (min) & Assigned nucleoside \\
\hline 244.09 & 112.05 & 243.09 & 16.0 & $\mathrm{C}$ \\
245.08 & 113.04 & 244.07 & 28.7 & $\mathrm{U}$ \\
268.10 & 136.06 & 267.10 & 16.5 & $\mathrm{~A}$ \\
284.10 & 152.06 & 283.09 & 21.9 & $\mathrm{G}$ \\
298.12 & 166.07 & 297.11 & 20.9 & $\mathrm{~m}^{2} \mathrm{G}$ \\
247.09 & 115.05 & 246.08 & 28.7 & $\mathrm{D}$ \\
312.13 & 180.09 & 311.12 & 20.4 & $\mathrm{~m}^{2}{ }^{2} \mathrm{G}$ \\
258.11 & 112.05 & 257.10 & 16.3 & $\mathrm{Cm}^{\mathrm{m}}$ \\
298.12 & 152.06 & 297.11 & 22.3 & $\mathrm{GW}$ \\
509.19 & 377.16 & 508.19 & 20.6 & $\Psi$ \\
245.08 & 125.04 & 244.07 & 28.7 & $\mathrm{~m}^{5} \mathrm{C}$ \\
258.11 & 126.07 & 257.10 & 16.4 & $\mathrm{~m}^{7} \mathrm{G}$ \\
298.12 & 166.07 & 297.11 & 16.4 & $\mathrm{~m}^{5} \mathrm{U}$ \\
259.09 & 127.05 & 258.08 & 28.7 & $\mathrm{~m}^{1} \mathrm{~A}$
\end{tabular}


Table 2. List of all digested products experimentally observed for tRNA ${ }^{\text {PheGAA }}$, after individual digestion with RNase T1 and RNase A. Identified sequences were underlined in black.

${ }^{1} \mathrm{MS} / \mathrm{MS}$ identification was done considering loss of m/z 376 corresponding to loss of modified base yW

\begin{tabular}{|c|c|c|c|c|c|}
\hline $\begin{array}{c}\text { Theoritical } \\
\mathrm{m} / \mathrm{z}\end{array}$ & $\begin{array}{c}\text { Experimental } \\
\mathrm{m} / \mathrm{z}\end{array}$ & $\mathrm{z}$ & $\begin{array}{c}\text { Molecular mass } \\
\text { (Da) }\end{array}$ & $\begin{array}{l}\text { Migration time } \\
(\text { (min) }\end{array}$ & Oligonucleotide \\
\hline \multicolumn{6}{|l|}{ RNase T1 } \\
\hline 589.14 & 589.14 & +1 & 588.14 & 24.6 & CG \\
\hline 937.65 & 937.64 & +2 & 1873.29 & 77.6 & $A \cup U \cup A\left[m^{2} G\right]$ \\
\hline 765.13 & 765.13 & +2 & 1528.25 & 34.6 & CUCAG \\
\hline 900.18 & 900.17 & +1 & 899.18 & 65.6 & DDG \\
\hline 612.12 & 612.12 & +2 & 1222.23 & 26.3 & CCAG \\
\hline 940.16 & 940.15 & +2 & 1878.30 & 47.3 & {$\left[\mathrm{~m}^{7} \mathrm{G}\right] \mathrm{UC}\left[\mathrm{m}^{5} \mathrm{C}\right] \mathrm{UG}$} \\
\hline 590.12 & 590.12 & +1 & 589.12 & 39.8 & UG \\
\hline 608.11 & 608.10 & +2 & 1214.20 & 57.2 & {$\left[\mathrm{~m}^{5} \mathrm{U}\right][\psi] \mathrm{CG}$} \\
\hline 836.15 & 836.14 & +3 & 2505.40 & 35.3 & {$\left[\mathrm{~m}^{1} \mathrm{~A}\right] \mathrm{UCCACAG}$} \\
\hline 930.15 & 930.14 & +2 & 1858.29 & 49.6 & AAUUCG \\
\hline 756.64 & 756.64 & +2 & 1511.28 & 24.3 & CACCA \\
\hline \multicolumn{6}{|l|}{ RNase A } \\
\hline 632.62 & 632.61 & +2 & 1263.22 & 59.1 & GGAU \\
\hline 932.21 & 932.20 & +1 & 931.21 & 29.3 & $\mathrm{~A}\left[\mathrm{~m}^{2} \mathrm{G}\right] \mathrm{C}$ \\
\hline 461.10 & 461.10 & +2 & 920.19 & 49.0 & AGD \\
\hline 876.48 & 876.48 & +3 & 2626.43 & 52.2 & GGGAGAGC \\
\hline 617.17 & 617.17 & +1 & 616.17 & 23.6 & {$\left[\mathrm{~m}^{2}{ }_{2} \mathrm{G}\right] \mathrm{C}$} \\
\hline 784.15 & 784.14 & +2 & 1566.28 & 45.9 & $\mathrm{AGA}[\mathrm{Cm}] \mathrm{U}$ \\
\hline 721.15 & 721.15 & +3 & 2160.44 & 47.1 & $\left.{ }^{13} \mathrm{AA}[\mathrm{yW}] \mathrm{A}[\psi]\right]^{1}$ \\
\hline 984.67 & 984.67 & +2 & 1967.33 & 60.9 & GGAG $[\mathrm{m} 7 \mathrm{G}] \mathrm{U}$ \\
\hline 590.12 & 590.12 & +1 & 589.12 & 50.3 & GU \\
\hline 604.14 & 604.14 & +1 & 603.13 & 50.0 & $\mathrm{G}\left[\mathrm{m}^{5} \mathrm{U}\right]$ \\
\hline 933.19 & 933.19 & +1 & 932.19 & 48.2 & $\mathrm{G}\left[\mathrm{m}^{1} \mathrm{~A}\right] \mathrm{U}$ \\
\hline 789.14 & 789.14 & +2 & 1576.27 & 45.7 & AGAAU \\
\hline 268.10 & 268.11 & +1 & 267.10 & 18.5 & A \\
\hline \multicolumn{6}{|c|}{ Total Sequence } \\
\hline
\end{tabular}


For table of content Only

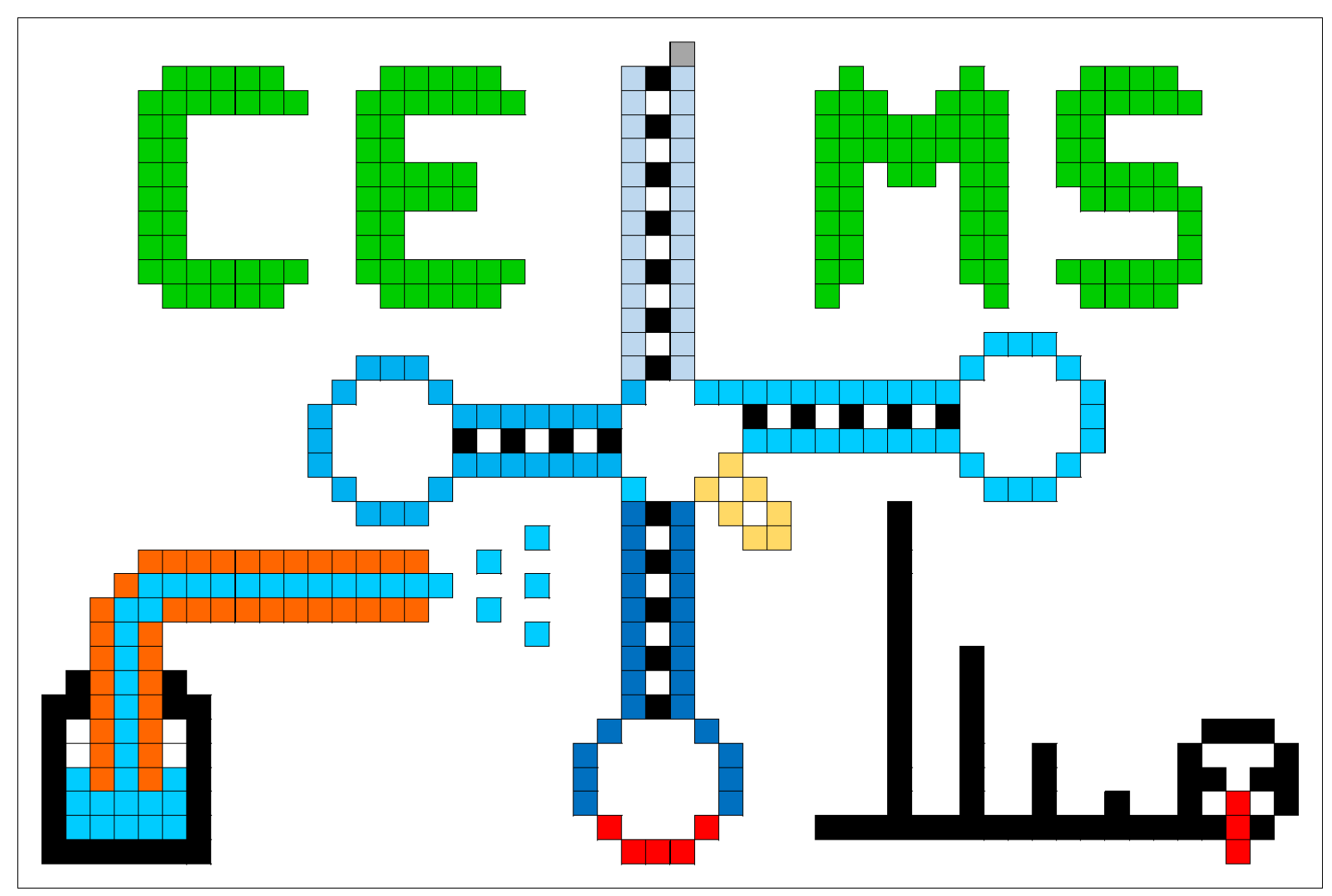

